\title{
What We Know and What We Do Not Know about Trust in Work Teams: A Systematic Literature Review
}

\author{
Catalina Diana Dumitru and Alexandra Mittelstädt
}

\begin{abstract}
Trust in work teams is a growing field of research. Numerous studies research trust in work teams in connection to team effectiveness and team performance. But this substantial amount of work lacks continuity and systematization in terms of conceptualization and operationalization. With this research project we take stock of the knowledge from previous studies and carry out a systematic review of the literature on trust in work teams. We analyze a total of 64 papers addressing trust in work teams, published between 1999 and 2019 (inclusive). In our review we focus on how trust in teams has been conceptualized and operationalized, how trust develops and is maintained in work teams, and on the tangled relationships between trust, distrust, and control. With this paper we contribute to the field of management and organizational studies by offering a theoretical framework of the antecedents of trust in work teams and by identifying current research gaps and future research directions.
\end{abstract}

Index Terms-organizational trust; work teams; systematic review; management.

\section{INTRODUCTION}

Are trust impressions enough to explain trust in teams? How do teams develop and maintain trust? For the past two decades, research on trust in teams has accumulated becoming a subdiscipline of organizational trust [1]. The literature on trust in teams has focused on the type of information that is being signaled in order to form shared trust beliefs and the advantages of developing team trust, its positive impact on team performance and team effectiveness [2], [3]. While empirical evidence on the topic of trust in teams accumulates, research still lacks continuity and systematization [4], [5]. In this paper we fill in the gap by systematically reviewing the literature, developing a comprehensive framework of the antecedents of trust in teams, and analyzing how trust develops and is maintained in work teams. Our findings provide insight into the differences that have been already pointed out in previous research and motivate future research to incorporate these ideas.

The team context offers the opportunity to understand how interpersonal trust interactions become standardized, enacted, and perpetuated by team members.

Published in June 2020

C. D. Dumitru, Bremen International Graduate School of Social Sciences, BIGSSS Jacobs University Bremen, Germany.

(e-mail: catalina.diana.dumitru@gmail.com).

A. Mittelstädt, Bremen International Graduate School of Social Sciences, BIGSSS Jacobs University Bremen, Germany.

(e-mail: amittelstaedt@bigsss-bremen.de).
This explains why it is possible to maintain trust even when team members and managers change or leave the team. Although based on dyadic interactions, trust in teams develops and persists as the relationships between team members grow. If trust in teams is different than interpersonal trust, it has different antecedents and is more than the sum of team members' trust impressions. This paper systematically analyzes the empirical evidence to understand how to reconcile these two options. What does the empirical evidence show? How is trust operationalized and measured in the literature? What are the main topics of research and where are the research gaps?

We begin by reviewing the three main models that explain trust development in teams: the interpersonal model of trust development [6]; swift trust model [7], and transformational model of trust [8]. We analyze their strengths and weaknesses, emphasizing the need to systematically analyze and review the empirical work on trust in teams. Then we describe the procedure by which we selected and analyzed the articles. Afterwards we present our findings focusing on how trust in work teams has been conceptualized in terms of antecedents and consequences, how trust develops and is maintained in work teams, and the relationship between trust, distrust, and control. We then discuss the theoretical implications and conclude with future research directions.

\section{LITERATURE REVIEW}

There are three main models that have been applied to explain how trust in work teams develops from interpersonal interactions between team members. In the following we review their assumptions and limitations highlighting how and why these models can be applied to the work team context.

\section{A. Interpersonal model of trust development}

Mayer, Davis, and Schoorman [6] propose an integrative model that revolutionized scholarly thought on organizational trust and remains the most frequently cited and widely applied framework on trust [53]. First, this model synthesizes previous research and proposes a model that explains how interpersonal trust develops between trustor and trustee, emphasizing that trust is not about reducing vulnerability and risk, but about positively accepting vulnerability and expecting that the other will behave in a positive way. Second, it conceptualizes trust as a cognitive construct distinguishing between the antecedents (propensity to trust and trustworthiness), the trust belief, the decision to trust, and the trust behavior. Third, it contains a feedback loop to explain how trust behavior reinforces future trust perceptions. 
While both positive expectations and the willingness to be vulnerable are at the core of this model of trust, most psychological and organizational research on trust focuses on positive expectations because they are easier to operationalize [9]. Positive expectations refer to the belief that the other party is trustworthy, and comprise three indicators of trustworthiness: ability, benevolence, and integrity. Ability or competence refers to the other party's capabilities in terms of skills and knowledge to carry out their tasks and to perform their job; benevolence indicates a personal degree of kindness toward the other party and a genuine concern for the other's welfare; and integrity reflects the adherence to a certain type of principles acceptable to the other party [6]. This is a cognitive or rational model of trust development because trustors evaluate the other party according to these three indicators: ability, benevolence, and integrity.

The cognitive evaluation translates into a decision to trust comprising the willingness to be vulnerable. This means acting based on both perceptions of trustworthiness and on other internal and external factors, such as personal preferences, experience, and organizational information [6], [10]. The information and knowledge that the trustors collect from external factors allow them to make themselves vulnerable not only because of the belief that the other party cares, but also because the other party will perform an action or behavior that is important to them [10].

The decision to trust does not necessarily translate into an action or behavior. The intention to accept vulnerability and the actual risk-taking behavior are different concepts and some scholars even consider risktaking as a totally different concept than trust, and one that should be treated separately [11]. As observable manifestations of trust, Gillespie and Mann [12] have broken trust behaviors into two components: reliance and disclosure. Reliance refers to the extent to which the trustor counts on the trustee's skills and knowledge and delegates tasks while disclosure is about how much sensitive or personal information the trustor is willing to share with the trustee [12].

This model explains trust as a unidirectional process of gathering information, developing impressions, and making decisions. Trustors look for good reasons to trust to make decisions about who is trustworthy and who is not. Contextual information and relationship history are important. In trust relationships, there is always a context and a history, other team members that matter, and a meaning and an interpretation of the interaction and the relationship [8]. Also, the assumption is that trustors always have enough information and time to spend on collecting and developing trust impressions. Perceptions of trustworthiness do inform trustors about which indicators people look for to trust others, but not how they do this. An essential question is how people interpret this information so that it informs a decision [10].

Trust is assumed to develop in a linear, predictable way as perceptions about the trustworthiness of the trustee lead to the decision to trust, which leads to trust behavior that updates information about the trustworthiness of the other [8]. When it comes to maintaining trust, this model implies that once trust is built, it is rather stable because of the feedback loop. Trust is reinforced when the trustee acts according to the impressions made on the trustor. But this also means that much energy is consumed to maintain trust because trustors always evaluate trustees based on their actions.

In a follow-up article reflecting on their model and the research that followed, Schoorman, Mayer, and Davis [13] suggest that this framework can successfully apply to trust in other referents such as groups and organizations. "Our model was designed to understand the major factors that explain trust from not only the individual level but from the group and organizational perspectives as well" [13, p. 346].

\section{B. Swift-trust model}

Researchers have found that sometimes team members start their relationships with a high level of trust, so they argue that trust is assumed initially, taken-forgranted as the basis of relationships, and then verified and adjusted [14]. Sometimes, team members cannot develop trust based on personal experience, simply because they do not have enough time or information, so they use institutionbased or routine-based trust. For example, temporary teams, such as virtual, action, and intervention teams, must perform under different time and organizational constraints. These teams function on swift trust, a special type of trust based on professional rules, roles, and practices [7].

Meyerson, Weick, and Kramer [7] propose that a temporary team interacts as if trust were present, but then must verify that the team can manage expectations. Put differently, with limited time, the team assumes trust initially as a baseline for interaction, and later verifies and adjusts trust beliefs, accordingly, based on the work experience. Although swift trust can be a strong form of trust, it is conditional and in need of reinforcement and calibration by actions [15].

Instead of trust being a process of collecting information, swift trust is created from category-driven processes [16]. Team members will transfer or import their trust beliefs from information they already have (e.g., organizational structure, other co-workers) onto other members of the same department or organization, but whom they do not know personally and with whom they have no history of working together. Thus, team members confer trust in the absence of personal experience, using membership in teams and organizations, professional roles, and rules as proxies or substitutes for trust.

Swift trust demonstrates that identifying with another team member and categorizing him or her as a member of one's own team, influences how trust develops within the team, an idea that is in line with psychological research related to social identity theory [17]. Researchers argue that this shift from personal identity to team identity makes team members more likely to trust others who share membership in the same team or organization [18]. But the downside is that it becomes more likely that team members will engage in stereotyping and be more biased in their judgements of their own team and organization [19]. Also, this makes it possible for team members to reject or disregard information that is not in line with their beliefs about other members of their team, which can have detrimental effects such as those associated with groupthink [20].

Professional roles, rules for interactions, and practices are important foundations for developing swift trust. Reliance on clearly defined roles makes trustful interactions possible even when these interactions are 
relatively isolated and transient, as in project work. Roles provide information about category members and are both granted and accepted. What is more, they contain information and implicit assumptions about the trustworthiness (e.g. competence) of that team member. For example, a person who occupies the role of team manager appears competent and has the intention of fulfilling the demands of this role. Roles are trust facilitators because they reduce uncertainty about the other team members' intentions and competencies. The rules are shared in the organizational environment and enable team members to behave in a trustworthy manner, even without direct contact, because one's membership in a team or organization implies an acceptance of the implicit and explicit "rules of the game" [21].

Swift trust in teams is considerably less developed and established than interpersonal trust [18]. Researchers consider that presumptive or swift trust is weak and fragile and depends on communication structures in the team and that it is necessary but not sufficient for communicating trustworthiness [22]. Other scholars think that swift trust is not a "true" form of trust but a substitute for trust-for example, such as a risk management strategy that might even inhibit the formation of trust between team members [23], [24]. While forming trust impressions in this way requires less time and less effort, it also tends to be less accurate due to shortcomings (e.g., bias, stereotyping, groupthink) of categorization processes [18], [24].

Nevertheless, swift trust considers the importance of shared team membership, professional roles, and practices as facilitators of trust in the absence of personal experience. But this conceptualization raises questions such as: Where do team rules and routines come from? Who influences them? What is the influence of those using them? Although swift trust offers an important perspective, it does not sufficiently explain how team members develop and maintain trust in interaction.

\section{Transformational model of trust development}

Building on previous research, Lewicki and Bunker [25] conceptualize organizational trust development and maintenance as a progressive, three-stage process made up of calculus-based trust, knowledge-based trust, and identification-based trust. The main assumption of this model is that trust is a transformational process that evolves in line with experience and information about the other. The authors emphasize that the transformational model of trust applies to understanding initial trust development between parties who have no experience with each other, where there is a high level of uncertainty and vulnerability about their professional relationship.

Within the first stage of a work relationship, calculus-based trust develops between team members. At this stage, trust is more of a cost-versus-benefit type of relationship. In this view, trust develops because of the benefits that team members gain. Consistency of behavior is crucial at this moment, so team members will act according to what they said or promised. This behavioral consistency is enforced by the threat of losing the relationship. The authors underline the fragility of trust at this initial stage of interaction.

As the relationship progresses, it moves into the next stage, that of knowledge-based trust. At this stage, team members can better predict each other's behavior through direct observation and relationship history. By now, enough repeated interactions between team members have happened to enable interpreting and predicting each other's behaviors. Through the accumulation of regular communication and information, team members are more likely to understand each other and predict behaviors. Therefore, trust at this point is not so easily broken by inconsistent behavior.

At the third stage, identification-based trust, trust rests on a high level of empathy between team members. After establishing consistency and predictability of each other's behavior, team members access a new level of interaction where they know, understand, and connect emotionally with each other in terms of values and emotions. This form of trust enables a correspondence of knowledge. The authors mention four types of activities that strengthen identification-based trust, namely, developing a collective identity (e.g., a team motto, a shared vision); being located in the same building or area; creating joint products or goals (e.g., project objectives, new product) and committing to shared values [25].

Trust develops gradually as team members move from one stage to another, addressing how trust changes within work relationships over time. The main ideas of this model are that trust is an ongoing process that develops in interaction; and trust is not high or low, but qualitatively different from one stage to another. Not all relationships must reach identification-based trust to be productive; some well-functioning relationships remain in the knowledgebased trust phase. For example, in a team where task interdependence is low, knowledge-based trust is enough to keep the relationships going because team members only require some knowledge about each other's skills to be productive. There is no need to identify with each other's values because there is no need to act on each other's behalf. The opposite applies in a team where interdependence is high. This type of team requires identification-based trust because team members are constantly required to act and decide on behalf of one another.

An important implication for how trust develops in the context of teams is that the shift from one form of trust to the other requires a fundamental change of behavioral and perceptual paradigm. For instance, in moving from calculusbased to knowledge-based trust, a significant shift involves changing from perceptions of differences to focusing on the similarities between team members [25]. But researchers have yet to adopt the transformational model to examine trust in teams [1] because it requires an in-depth exploration. Support for the progression from knowledge- to identification-based trust, but not from calculation- to knowledge-based trust, has been found in trust in coworkers and teammates [26].

Several aspects of trust are important in the context of transformational models of trust. Trust matters from the beginning but is supposed to be rather weak initially and expected to build up gradually. It is an input and an output of relationship development. Second, the models emphasize that the parties must get to know each other through mutual experiences. While organizational rules and routines play their role, the relationship depends mainly on the process of developing trust and common expectations over time. Third, the frameworks suggest that relationships will become more stable and robust, once they successfully complete the trustinformation-control cycle [27], [28], or as they move from calculus-based to knowledge- and identification-based trust 
[25]. But when team members and managers are replaced or when assessments turn negative, trust may be lost, expectations may no longer match, and there is always the possibility of dissolving the relationship.

In conclusion, two possible explanations are offered for how trust in teams develops and is maintained: through personal experience, cognitive evaluation and affect development or through sharing membership and team roles and forming meanings and interpretations. Trust in teams originates in the interpersonal trust beliefs and feelings of team members (cognitive and affective models of trust), is built by accumulating information and managing impressions, and is maintained by behaving according to expectations. The other explanation according to the swift trust model is that trust is based on shared membership, roles, and routines. Team members enter work relationships with a high or moderate level of trust from the beginning, and then engage in an as if kind of trust, in which they assume trust initially as the basis of their work relationships. Because they are members of the same organization or profession, everyone acts in line with their professional roles, and follows institutional rules and routines. These categorization and identification processes allow for the team to function as if trust were present, and later verify and adjust trust accordingly (swift model of trust).

But these models explain dyadic relations in organizations. Applying these models to understand how building and maintaining trust happens in a team yields two possibilities: to assume that trust in teams is an extension of interpersonal trust or that trust in teams is qualitatively and functionally different. If trust is an extension of interpersonal trust between team members, it is a sum or aggregate of trust impressions about each team member based on personal experience (cognitive and affective models of trust) or it is a team characteristic that develops from shared membership, professional roles, and organizational rules (swift trust model).

Having reviewed the theoretical models, examining the empirical evidence on the nature of trust in teams follows. A comprehensive overview of the literature on trust in the context of work teams, results in answering the following research question: How have previous researchers conceptualized and measured trust in teams? How does trust in teams develop and is maintained? We follow a systematic review of the literature to answer these questions. Additionally, this review not only maps out the literature but also identifies research gaps and informs future studies.

\section{Methodology}

A systematic review is a reliable method for obtaining an overview of the research on a topic, or for bringing together different research strands, using a reproducible, consistent method of analyzing data [29]. Having its origins in medical and healthcare sciences, where it is used to evaluate the effectiveness of interventions and treatments, other disciplines have adopted and adapted the systematic review, including social sciences and management and organization studies [30]-[32].

Our review follows the method developed for management and organization studies by Denyer and Tranfield [33] and for social sciences by Petticrew and Roberts [30]. The method includes four stages: problem formation, article selection, summarizing, and interpreting the findings.

The first stage, problem formation, clarifies the concepts, the context, and the research questions that guide the construction of the search strings. An extensive database of articles was achieved by merging two streams of literature, trust and work teams, and constructing search strings for each term. For example, the Boolean search string for trust is: "trust" OR "trustworthiness" OR "interpersonal trust" OR "benevolence" OR "competence" OR "integrity" OR "uncertainty" OR "risk" OR "vulnerability" OR" cooperation". The main search string for teams is: "team* in the workplace" OR "work group*" OR "work team*” OR "teamwork" OR "team process*" OR "group* dynamic*" (asterisk for truncated terms). The two streams are merged with AND, followed by focusing next on selection of peer-reviewed articles published from 1999 until 2019. Nine databases are selected to ensure data saturation: Academic Search Premier, Business Source Premier, Communication and Mass-Media Complete, Humanities International Complete, SocIndex, Computers and Applied Sciences Complete, EconLit, PsycInfo, PsycArticles, a representative sample for high-impact research published on trust in teams. These specific databases reflect a high publication quality, and present only peer reviewed literature, considered to have a higher level of quality, standardization and reliability than secondary sources and grey literature (Briner \& Denyer, 2012). The 6,943 articles retrieved by title and keywords are screened and all the articles, in which the key terms are variables in the studies are kept, and all others excluded. In total, 328 articles are considered for the review. After obtaining full text copies of the 328 articles, they are read and evaluated as the review methodology requires [34]. Based on reading the abstract and the full-text and checking for consistency in the working definitions of trust and teams, a total of 64 articles are determined relevant for the analysis.

In the summarizing and interpretation phase, data is extracted about conceptualization, theory, antecedents, and measurement of trust in teams from the relevant articles $(\mathrm{N}=64)$. Using the $\mathrm{R}$ narrative coding software, the articles are categorized and analyzed to provide an in-depth, systematic overview of the research area. Extracting the relevant data from the articles, focused on specific categories: conceptualization, antecedents of trust, trust development and maintenance.

Summarizing and interpreting the articles produced a clear, more organized picture of what is happening in the literature on trust in teams. Mapping this literature offers a great opportunity to identify research gaps. Where can consistency be identified, and how does this steer the direction of future research? First, an overview of the research field, presents the patterns and assumptions throughout the literature, concluding with a discussion on research gaps and future research directions.

\section{FINDINGS}

Friedlander [35] published the first study on trust in teams and since then the number of publications on this topic has been steadily growing, with the highest number of studies published in the past 20 years from 1999 to 2019 (almost 74\%) and increasing. When it comes to article type, $77 \%$ are empirical and focus on theory-testing, while $19 \%$ are empirical theory-building, and $4 \%$ are theoretical papers. 
Of four broad streams of literature, the biggest comes from organizational studies, followed by communication studies (i.e., the impact of computer-mediated communication on trust), project management (i.e., collaboration and conflict management) and information systems (i.e., the effects of remoteness on collaboration and trust in teams).

Recently reviews and meta-analyses on trust in teams aiming to summarize and integrate the state of the field have increased, which means that scholarly work on the topic has accumulated and become a field of its own. This includes a comprehensive review on trust in work teams as a multilevel construct [1]; a meta-analysis on the relationship between team trust and team performance by De Jong, Dirks, and Gillespie [3]; a meta-analysis on the relationship between team trust and team effectiveness in virtual teams by Breuer, Hueffmeier, and Hertel [2]; and a review on trust in teams at multiple levels of analysis [5].

Team type is important. The empirical studies focus mostly on ongoing teams at the beginning of their relationship, usually during the socialization phase and are concerned with how team members form impressions of each other, as this is considered a predictive indicator of how they will work together in the future [36]. As Figure 1 below shows, researchers focus predominantly on trust in two types of teams - ongoing, face-to-face teams and temporary, virtual teams-because comparing how trust evolves differently in these contexts shows how teams deal with perceived risks [2], and how different factors influence the development of trust (e.g., computer-mediated communication, information salience). Other types of teams examined are self-managing teams, cross-functional teams, and top-management teams.

\section{Team type}

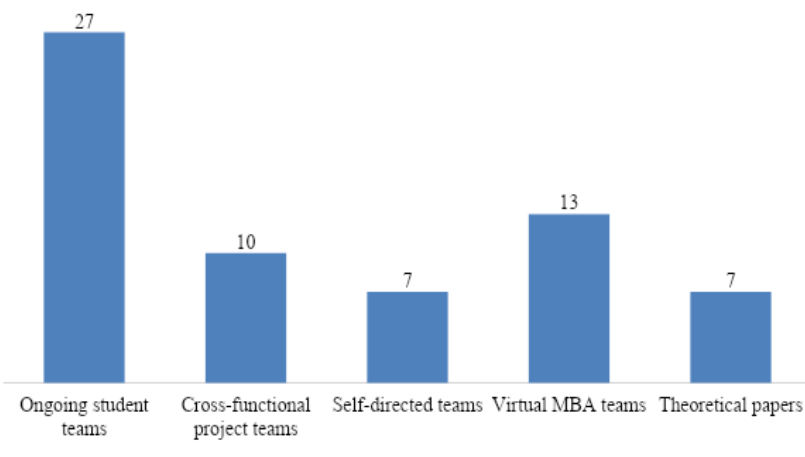

Figure 1. Distribution of articles according to team type

However, most of the teams examined are student teams (see Figure 1 above). Seldom do researchers look at teams in working environments, nor do they consider that these teams are embedded in an organizational context that exerts its influence on team and trust development. Gaan [37] and Lander, Purvis, McCary, and Leigh [38] are notable exceptions. Gaan [37] analyzes 25 virtual teams working in several IT companies in India, and shows that organizational collaborative tools (i.e., blended approaches, organizational policies, and process orientation) influence team trust and virtual-team performance. Lander et al. [38] explore in a case study how organizational tools (i.e., communication practices) influence trust building in outsourcing teams, interviewing 17 team members, project managers, and outsourcing managers about their trust practices.

Regarding measurement and research designs, an overwhelming number of studies are quantitative and experimental, and only a few are qualitative. Researchers measure trust in teams mostly using quantitative methods (i.e., surveys, experiments) by aggregating individual responses to the team level after calculating the withingroup agreement coefficient under the assumption that trust is a shared belief of team members [39]. Recent reviews stress that researchers must specify the level and referent [9] and be consistent in the level of analysis and the level of measurement with the conceptualization chosen [40].

\section{A. Conceptualizing and operationalizing trust in} teams

There is no commonly accepted definition of trust in work teams. Team trust or intra-team trust [41]; swift trust [7], collective trust [42], and trust in groups [43] refer to trust in the context of teams or work groups in organizations [44]. The literature differentiates based on referent. Intra-team trust is trust that exists within one distinct team (where the referent can be another team member, the team as a whole, or the team manager) and inter-team trust, is trust that exists between two interacting teams (where the referent is another team) [9], [5].

Most researchers assume that trust is an isomorphic construct [45], [46], therefore trust in teams is an extension of interpersonal trust; the sum of the interpersonal trust between team members [9]. For instance, in developing their theory on trust, monitoring, and cooperation in interpersonal and intergroup relationships, Ferrin and colleagues adopt the concept of isomorphism, stating that although trust might differ in structure it has similar functions across levels [47]. Conceptualized as an extension of interpersonal trust, researchers draw mostly on rational and affective models of trust [6], [48], focusing on how perceived trustworthiness indicators (i.e., ability, benevolence, and integrity) enable team members to develop trust with each other. Both dimensions of trust, cognitive and affective, increase the ability of team members to work together [49]. Trust develops both through cognitive evaluations and as team members make emotional investments in relationships, express concern for the well-being of others, and come to believe that these feelings are reciprocal [50].

Review papers by Fulmer and Gelfand [9], Costa, Fulmer, and Anderson [1], and Nienaber et al. [5] propose that trust is a quasi-isomorphic phenomenon that occurs when constructs and relationships function in similar ways at different levels. According to the authors, many of the definitions across levels and referents generally represent trust as including positive expectations of trustworthiness, willingness to accept vulnerability, or both. At the same time, there are differences in the construct at different levels. Trust at the team and organizational levels denotes shared collective beliefs and attitudes from members within a unit. Trust at the organizational level is a shared climate, different from trust at the individual level as an individual's psychological state [9]. Trust in teams is complex, multilevel and contains both interpersonal trust between team members and collectively shared trust in the team as a unit. Over time, through repeated team interactions, and based on the interpersonal trust between each other, team 
members develop shared beliefs about the trustworthiness of the team as a whole. Emergent team states [51] and compositional models [52] are possible theories to explain and measure how trust develops from individual to shared trust beliefs in teams.

But challenges to conceptualizing trust as a quasiisomorphic concept come from the concept of sharedness. What does "shared" mean and is it realistic to assume that team members have similar perceptions of trustworthiness within the team? What happens when there is disagreement? What are the advantages and disadvantages of having similar perceptions? Research by De Jong and Dirks [41] points to trust asymmetry and monitoring dissensus in student association teams, while Fulmer and Ostroff [53] talk about trust convergence and divergence. Naquin and Kurtzberg [54] demonstrate that perceptions of team trust are lower than the average ratings of individual trust and statistically equivalent to the least-trusted team member. Basing their argument on both the negativity bias and the discontinuity effect, the authors demonstrate that team members focus most on the least trustworthy individual member of a team when making judgments about collective team trust. This indicates that teams develop configurations of trust beliefs rather than shared beliefs of trustworthiness. When trust in teams is explained as the shared beliefs of team members, these can be directed toward different referents - a coworker, the team manager, or the team as a distinct unit - and can have different meanings over time. These trust beliefs exist because of the actions of team members, managers, and consultants, because of their interactions, and the organizational systems in which these interactions are embedded.

Conceptualizing trust in teams as shared beliefs of trustworthiness overlaps with the concept of team psychological safety [55]. What is the difference between shared trustworthiness beliefs and team psychological safety? These two concepts have much in common; they describe psychological states involving shared perceptions about the trustworthiness of team members. Psychological safety refers to the shared beliefs that speaking up and admitting mistakes and failures will be valued (i.e., benevolence and integrity toward the team). The concepts refer to the same level of analysis - the team - and all have positive consequences for teams and organizations. Edmonson discusses the two concepts and argues that they differ when it comes to the object of focus, in that while trust is about how a team member perceives others, psychological safety is about how others perceive a team member. As to the concept of trust in teams, she considers it an extension of interpersonal trust and, therefore an antecedent of psychological safety [20]. Shared beliefs are antecedents or factors influencing trust in teams, but not trust itself.

\section{B. Development and maintenance of trust in teams}

The empirical studies reviewed show that team type influences how trust develops and is maintained. In ongoing teams, trust develops gradually from information cues and signals. Temporary, virtual teams, with time and project constraints, assume trust initially and then adjust accordingly. Depending on the characteristics of the team, trust in teams takes two distinct forms with distinct antecedents: interpersonal trust between team members (in ongoing teams) leading to shared beliefs at team level, and swift trust (in temporary, project, and virtual teams). As
Figure 2 below shows, the antecedents of interpersonal trust and swift trust in teams are different.

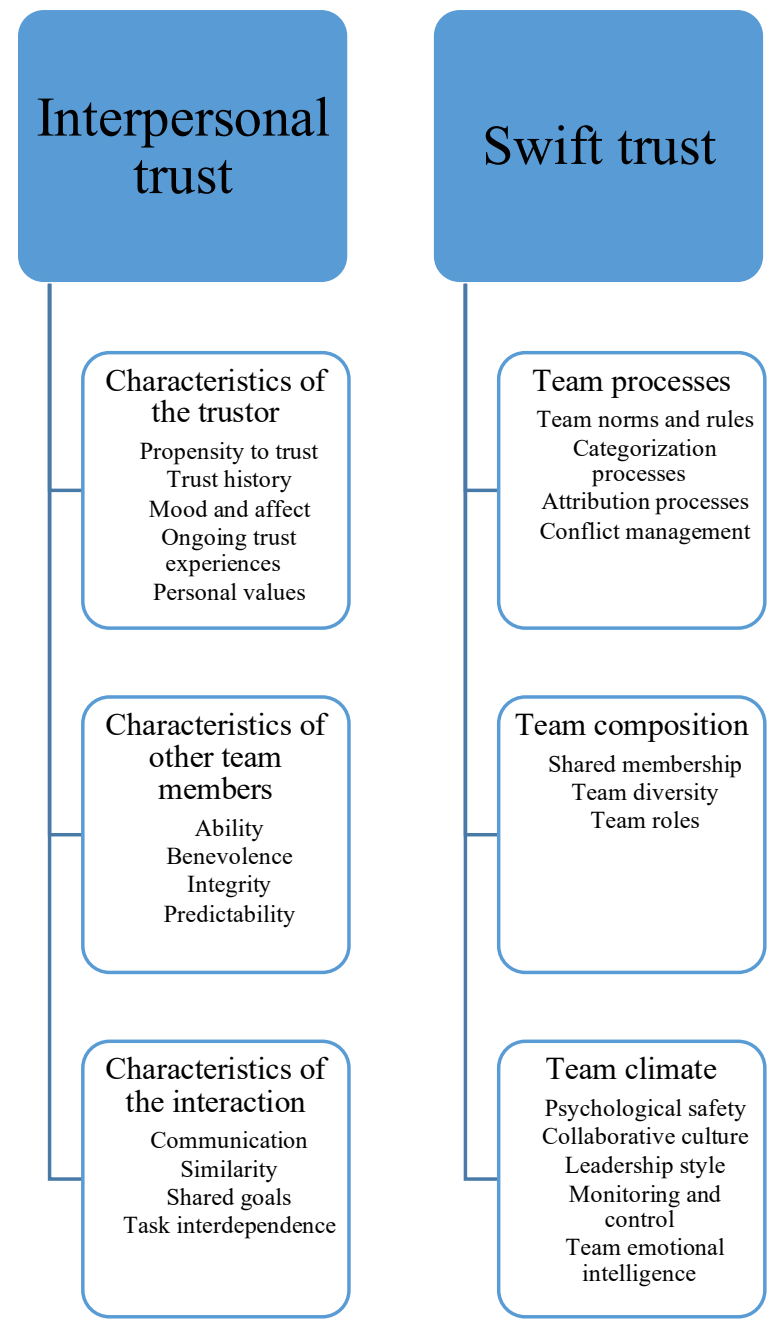

Figure 2. Antecedents of interpersonal trust and swift trust in teams

This illustration of the antecedents of interpersonal trust in teams and swift trust shows the different factors that influence how trust develops, depending on team type (Figure 2). In ongoing teams, members form trust beliefs that stem from their own personality (e.g., propensity to trust, personal values, affect), from the characteristics of other team members (e.g., ability, benevolence, integrity), and from characteristics of the interaction between team members (e.g., communication, shared goals). In temporary and virtual teams, team members do not have enough time to build trust beliefs based on personal experience, so they assume trust from professional roles (i.e., categorization, attribution), shared membership (i.e., functional diversity), and team climate (i.e., psychological safety, monitoring).

First impressions play a critical role in perceived trustworthiness for interpersonal trust development in teams. Zolin, Hinds, Fruchter, and Levitt [56] examined interpersonal trust development in project teams and found that team members indeed rely on early, first impressions of perceived trustworthiness when they evaluate how the other team members are delivering on commitments (see Figure 2 ). This evaluation is critical, especially at the beginning of the team members' interactions, when reliable information about performance might be lacking or difficult to interpret.

Few studies look at nonverbal cues that are important in making first impressions. Trust in virtual teams 
is difficult to build because of the absence of nonverbal cues [57]. In ongoing teams, nonverbal cues influence emotion contagion and have a ripple effect [58]. When nonverbal indicators are congruent with the message communicated, research in experimental trust games shows that nonverbal cues inform trust decisions [59]. Genuine smiles, direct eyecontact, and nodding are nonverbal cues that induce trust [60]. On the other hand, gaze aversion, leaning back, crossing arms, and pauses are interpreted as signals that indicate untrustworthiness [60].

Several studies by Jarvenpaa, Knoll, and Leidner [61] offer empirical support that ability, benevolence, and integrity are associated with trust in virtual teams. Additionally, the authors find that communication plays an important role increasing team trust [22]. Information salience and relevance have also been considered important antecedents for the development of trust in teams [62]. Similarly, information symmetry and good communication are described as antecedents of team trust formation [63].

Williams [50] presents an affective-cognitive model of trust development highlighting group membership, affect, and perceived trustworthiness as mechanisms for the development of trust in teams. Through the psychological mechanisms of social- and self-categorization, group membership influences the extent to which members who belong to a certain team will tend to trust each other more than they do members of other teams. Additionally, similar group membership is associated with generating positive feelings [50].

Few studies look at how trust in teams is maintained perhaps because once trust is built it is assumed to be rather stable with few changes over time, as it sustains itself through a feedback loop [13]. One such study by Lisa van der Werff and Finian Buckley [26] tracks cues of trust development during the socialization phase of accountant trainee teams in a Big 4 Irish company. They find in a longitudinal study that coworker trust development is nonlinear, with faster rates of growth at the beginning of a relationship when employees are just getting to know their coworkers. The results of their research show no clear evidence for swift trust, not surprising since swift trust as defined exists in temporary teams. Over time, ability and benevolence have a greater and more consistent effect on the overall trust in coworkers than rules and team identification [26]. Another study by Zornoza, Orengo, and Peñarroja [64] explores the moderating role of trust in virtual teams in an experimental longitudinal design. Their results indicate that in virtual teams, team trust climate (conceptualized as trust perceptions shared by team members) moderates the relationship between group-process satisfaction and group cohesion. From interpersonal trust perceptions, team members develop a shared trust climate when team members' perceptions converge [64], [65].

Organizational factors also play an important role but this has seldom been explored. A recent field study by Baer et al. [66] looks at situational normality and situational aesthetics, and how these influence the perceived trustworthiness of the organization. They find that aspects such as the degree to which the work setting appears customary, with everything in proper order, and the degree to which the work setting has a pleasing and attractive appearance shape newcomer trust formation.

C. Trust, distrust, and control in teams
Throughout the literature, the underlying assumption is that the more trust, the better. Trust fosters collaboration and cooperation between team members [3], and a lack of trust translates into team monitoring, duplicating work, and documenting problems [67]. But upon closer examination, the meanings and interpretations of team members and the phase of project development determine when control is interpreted as positive and expected, building and maintaining trust, and when control is interpreted as negative and means a lack of trust.

Researchers have focused on the positive impact of trust in teams on team outcomes. Evidence from several meta-analyses on trust in teams demonstrates the impact of perceived trustworthiness and propensity to trust, and their direct effect on team effectiveness and team performance [2], [3]. The findings confirm that team trust is positively related to and has a moderately large impact on team performance [3]. The relationship between trust in teams and team performance is stronger in virtual than in face-toface teams, and weaker when team interactions are documented, as compared to no such documentation [2]. It may seem counterintuitive, but the relationship between trust in teams and team effectiveness is stronger in virtual teams than in colocated teams, because virtual teams perceive higher risk, and the need to build trust is thus stronger.

The literature on trust in teams focuses exclusively on trust, but research on distrust in teams is equally relevant and might offer results that could have an important impact on the field [1]. The systematic review of the literature yielded two interesting studies that analyze the role of distrust in work teams. Lowry, Schuetzler, Giboney, and Gregory [68] demonstrate in an experimental study that virtual teams in which the initial condition was distrust significantly outperformed all control groups in non-routine decision-making tasks. This is because distrust raises awareness between team members, making them challenge each other and raise questions, which is beneficial for creative, nonroutine tasks, but detrimental for standard, routine tasks. Tanghe, Wisse, and van der Flier [69] show that distrust can positively affect teams, depending on the context and the team tasks, some of which make distrust productive and beneficial for team effectiveness.

There are two perspectives on the relationship between trust and distrust: trust is a continuum or a bipolar construct; or trust and distrust are different constructs. In the first perspective, trust varies from high trust to low trust or distrust, according to the level of experience and interaction between trustor and trustee, and any decrease in trust moves people closer to distrust [18]. Accordingly, most models of trust development - e.g., the stages of the trust development model [25] or the conditional and unconditional model of trust [70]-imply that trust starts from zero and develops either into high or low trust. Not many theories address what the midpoint of this continuum might be, whether it represents moderate trust and distrust at the same time, or whether a midpoint is relevant for trust [18].

The second perspective is that trust and distrust are different concepts with different antecedents. Lewicki, McAllister, and Bies [71] argue that trust and distrust are different constructs. Trust and distrust have distinct antecedents and consequences and consist of different expectations: while trust refers to positive expectations about the behavior of another team member, distrust is about 
negative expectations [71, p. 439]. In fact, Lewicki et al. [71] consider that the opposite of trust is not distrust: the two constructs are unique and both range on different continuums from high to low.

Moreover, Lewicki et al. [71] present arguments for why it is more likely that, in the work environment that entails multiplex and ambivalent working relationships, team members experience both trust and distrust of the same team member for different aspects or tasks and in different contexts. Mayer et al. [6] also discuss trust as context specific, i.e., a person can be trusted in one domain but not in another. For instance, one team member might trust another to perform a regular, routine task, but might distrust the same team member when it comes to a new, nonroutine task. In return, this distrust might actually have a positive outcome on the overall performance of the team, as they might spend less time on monitoring that team member's activity by assigning the task to a member that they trust, and spend more time on their own task. The authors argue that it is rather idealistic to assume that team members should always trust each other, and that distrust, i.e., monitoring, has an important part to play in maintaining healthy work relationships [71, p. 444].

Trust in teams and team monitoring have an intricate relationship that depends on context and meaning. Team monitoring, understood as the extent to which team members check up on each other, is a sensitive issue in teams because it can undermine solidarity and tends to be interpreted as a lack of trust [72]. Team monitoring leads to trust and has a positive meaning in teams when it is expected-for instance, in working contexts where there is little or no information available [47]. Also, trust and monitoring can relate differently at different stages of a project - that is, negatively at the start but positively both in the middle and toward the end of the project [39].

Piccoli and Ives [36] show that trust declines in virtual teams that have control mechanisms in place by increasing vigilance and salience. Costa and Anderson [39] conceptualize monitoring as a component of trust in face-toface, ongoing teams. For self-managing teams, team monitoring is important - when team members have a high task autonomy and trust each other and do not monitor each other's work their team performance decreases [72].

\section{DISCUSSION}

Research in the past 20 years has come a long way in discovering how trust in teams develops and is maintained. The empirical studies discussed here demonstrate that team type, organizational context, meaning, and interpretation determine how trust in teams develops and is maintained. Several gaps and future research directions are addressed below.

Team characteristics determine what form trust takes and how it develops and is maintained. But teams exist in organizations with tools and systems that support and influence their development. Little research has focused on the context in which the relationships between team members are embedded and the types of organizational tools and systems that support the development and maintenance of such interactions. Context is important because it determines how trust develops and is maintained [73].

First impressions greatly influence trust building, and first impressions of trust come from nonverbal cues as well [60]. Few studies pay attention to nonverbal behavior, although it is a component of building first impressions [56].

A common assumption throughout the literature is that if teams develop shared trust beliefs, team members will act more trustingly within the team. However, not well understood is what "shared" means exactly to team members and whether it is realistic to assume that teams develop shared beliefs, or rather configurations of trust. More is known about the factors that influence the development of trust in teams and the relation between team type and trust development.

Most research has focused on how trust is built and not on how trust is maintained in teams - more precisely, which activities and interactions build and maintain trust in teams, and what meanings these activities have for team members. Also, this systematic review reveals that the meanings and the interpretations that team members give to their interactions determine what type of actions build trust and what type of actions signify lack of trust [68] and these meanings and interpretations are built in interaction.

Some common ideas emerge concerning the tangled relationship between trust, distrust, and control in teams. The assumption throughout the literature is that the more trust is fostered in teams, the better the team functions [1]. Recently, a few empirical studies have pointed to the beneficial effect of distrust in virtual teams for nonroutine tasks [68], [69]. Also, control structures are important and interpreted positively, depending on the organizational context, the type of team (e.g., in virtual and self-managing teams, monitoring is positive and expected), and stage of the project (e.g., control is interpreted negatively in the beginning of the project and positively in the middle and toward the end of the project).

Researchers have asked team members and managers of predominantly virtual and face-to-face student teams about their perceptions of trust in teams. Little research focuses on cross-functional teams in practice, although evidence indicates that this is a challenging context for building and maintaining trust [74], [75]. The perspective of team consultants, experts in working with different types of teams to build and maintain trust, remains unexplored. The consultants' perspective is important; while team members' and managers' main activity is to perform organizational tasks, the consultants' main activity is to develop teams and projects [76]. Team consultants' perspective becomes vital because they can provide rich accounts of how they help team members and managers build and maintain trust in different types of teams across organizations.

Although conceptualized as a process, trust is most often measured at one point in time, a methodological decision that does not reflect the complexity of trust as a process [8], [73]. Researchers take a static and quantitative approach to trust, focusing on the individual beliefs and perceptions of team members regarding team processes and disregarding observed behavior and team interactions. Qualitative approaches are rare and observational studies are non-existent. Jones and Jones [77] and Lander, Purvis, McCary, and Leigh [38] are notable examples of ethnographic studies. This lack of qualitative studies results from the challenges of collecting longitudinal and observational data in companies. But such studies could offer an important contribution to the field by capturing the meanings, the interactions, and the activities, in which team 
members engage as they unfold in the work environment [78].

\section{CONCLUSION}

The currently available empirical evidence is largely grounded in the conceptualization of trust in teams as shared beliefs of team members about the trustworthiness of the team as a distinct unit. Much less information exists about the meaning and interpretation of trust in teams among team members, regarding the activities in which they engage to build and maintain trust, and the practices by which trust gets produced and reproduced. A more interesting question than what type of collected information makes team members develop shared beliefs and decide to trust each other is the question of what planned activities engage them in building and maintaining trust and what meanings these activities have for team members. We encourage researchers to explore these research questions in order to gain insight into how team members develop shared trust beliefs.

\section{ACKNOWLEDGMENT}

We wish to thank BIGSSS and DAAD for funding, Prof. Guido Mollering, Prof. Margrit Schreier, and Prof. Hwee Hoon Tan for their helpful comments and suggestions.

\section{REFERENCES}

[1] A.C. Costa, C. A. Fulmer, and N. R. Anderson, "Trust in work teams: An integrative review, multilevel model, and future directions," Journal of Organizational Behavior, vol. 39, no. 2, pp. 1-16, February 2018

[2] C. Breuer, J. Hueffmeier, and G. Hertel, "Does trust matter more in virtual teams? A meta-analysis of trust and team effectiveness considering virtuality and documentation as moderators," Journal of Applied Psychology, vol. 101, no. 8, pp. 1151-1177, August 2016.

[3] B. A. De Jong, K. T. Dirks, and N. Gillespie, "Trust and team performance: A meta-analysis of main effects, moderators and covariates" Journal of Applied Psychology, vol. 101, no. 8, pp. 1134 1150, August 2016.

[4] C. D. Dumitru and M. A. Schoop, M. A. "How does trust in teams, team identification, and organisational identification impact trust in organisations?," International Journal of Management and Applied Research, vol. 3, no. 2, pp. 87-97, March 2016.

[5] A. M. Nienaber, M. Holtgrave, and P. D. Romeike, "Trust in teams: A review across levels," in The Routledge Companion to Trust, R. H. Searle, A.-M. I. Nienaber, and S. B. Sitkin, Eds. Abingdon, OX: Routledge, 2018, pp. 89-107.

[6] R. C. Mayer, J. H. Davis, and F. D. Schoorman, "An integrative model of organizational trust," The Academy of Management Review, vol. 20, no. 3, pp. 709-734, July 1995.

[7] D. Meyerson, K. E. Weick, and R. M. Kramer, "Swift trust and temporary groups," in Trust in Organizations: Frontiers of Theory and Research, 1st ed., R. M. Kramer and T. R. Tyler, Eds. Thousand Oaks, CA: Sage Publications, 1996, pp. 166-195.

[8] R. J. Lewicki, E. C. Tomlinson, and N. Gillespie, "Models of interpersonal trust development: Theoretical approaches, empirical evidence, and future directions," Journal of Management, vol. 32, no. 6, pp. 991-1022, December 2006.

[9] C. A. Fulmer and M. J. Gelfand, "At what level (and in whom) we trust: Trust across multiple organizational levels," Journal of Management, vol. 38, no. 4, pp. 1167-1230, May 2012.

[10] D. M. Rousseau, S. B. Sitkin, R. S. Burt, and C. Camerer, "Not so different after all: A cross-discipline view of trust," Academy of Management Review, vol. 23, no. 3, pp. 393-404 1998.

[11] G. Möllering,Trust: Reason, routine, reflexivity, 1st ed London, UK: Emerald Group Publishing, 2006.

[12] N. A. Gillespie and L. Mann, "Transformational leadership and shared values: The building blocks of trust," Journal of Managerial Psychology, vol. 19, no. 6, pp. 588-607, September 2004.
[13] F. D. Schoorman, R. C. Mayer, and J. H. Davis, "An integrative model of organizational trust: Past, present, and future," Academy of Management Journal, vol. 32, no. 2, pp. 344-354, April 2007.

[14] R. C. Ford, R. F. Piccolo, and L. R. Ford, "Strategies for building effective virtual teams: Trust is key," Business Horizons, vol. 60, no. 1, pp. 25-34, 2017.

[15] B. C. Crisp and S. L. Jarvenpaa, "Swift trust in global virtual teams: Trusting beliefs and normative actions," Journal of Personnel Psychology, vol. 12, no. 1, pp. 45-56, February 2013.

[16] R. M. Kramer, "Trust and distrust in organizations: Emerging perspectives, enduring questions," Annual Review of Psychology, vol. 50, pp. 569-598, February 1999.

[17] H. Tajfel and J. Turner, "The social identity theory of intergroup behavior," in Psychology of Intergroup Relations, S. Worchel \& W. G. Austin, Eds. Chicago: Nelson Hall, pp. 7-24, 1986.

[18] B. D. Adams, D. J. Bryant, and R. D. G. Webb, "Trust in teams: A review of the literature," Guelph, Ontario, Canada. Research Report, 2000.

[19] M. B. Brewer, "Managing diversity: The role of social identities," in Diversity in work teams: Research paradigms for a changing workplace, S. Jackson and M. Ruderman, Eds. Washington, DC: American Psychological Association, 1995, pp. 47-68.

[20] A. Edmondson, Teaming: How Organizations Learn, Innovate, and Compete in the Knowledge Economy. San Francisco, CA: John Wiley \& Sons, 2012.

[21] J. L. Wildman, M. L. Shuffler, E. H. Lazzara, S. M. Fiore, C. S. Burke, E. Salas, and S. Garven, "Trust development in swift starting action teams: A multilevel framework," Group \& Organization Management, vol. 37, pp. 137-170, April 2012.

[22] S. L. Jarvenpaa and D. E. Leidner, "Communication and trust in global virtual teams," Organization Science, vol. 10, no. 6, pp. 791815, December 1999.

[23] D. H. Mcknight and N. L. Chervany, "Reflections on an initial trustbuilding model," in Handbook of Trust Research, 1st ed., R. Bachmann and A. Zaheer Eds. Cheltenham, UK: Edward Elgar Publishing, 2006, pp. 29-51.

[24] D. H. McKnight, L. L. Cummings, and N. L. Chervany, "Initial trust formation in new organizational relationships," Academy of Management Review, vol. 23, no. 3, pp. 473-490, July 1998.

[25] R. J. Lewicki and B. B. Bunker, "Trust in relationships," Administrative Science Quarterly, vol. 5, no. 1, pp. 583-601, 1995.

[26] L. van der Werff and F. Buckley, "Getting to know you: A longitudinal examination of trust cues and trust development during socialization. Journal of Management, vol. 43, no. 3, pp. 742-770, March 2017.

[27] R. W. Boss, "Trust and managerial problem solving revisited," Group \& Organization Management, vol. 3, no. 3, pp. 331-342, September 1978.

[28] D. E. Zand, “Trust and managerial problem solving," Administrative Science Quarterly, vol. 17, no. 2, pp. 229-239, June 1972.

[29] A. Booth, D. Papaioannou, and A. Sutton, Systematic Approaches to a Successful Literature Review, 1st ed. London, UK: Sage Publications, 2012.

[30] M. Petticrew and H. Roberts, Systematic reviews in the Social Sciences: A Practical Guide, 1st ed., Malden, MA: Blackwell Publishing, 2006.

[31] C. Pickering and J. Byrne, "The benefits of publishing systematic quantitative literature reviews for $\mathrm{PhD}$ candidates and other earlycareer researchers." Higher Education Research \& Development, vol. 33, no. 3, pp. 534-548, 2014.

[32] D. Tranfield, D. Denyer, and P. Smart, "Towards a methodology for developing evidence-informed management knowledge by means of systematic review," British Journal of Management, vol. 14, no. 3, pp. 207-222, September 2003.

[33] D. Denyer and D. Tranfield, "Producing a systematic review," in The Sage Handbook of Organizational Research Methods, D. Buchanan and A. Bryman, Eds. London, UK: Sage Publications, 2009, pp. 671689.

[34] R. B. Briner, D. Denyer, and D. M. Rousseau, "Evidence-based management: Concept cleanup time?" Academy of Management Perspectives, vol. 23, no. 4, pp. 19-32, November 2009.

[35] F. Friedlander, "The primacy of trust as a facilitator of further group accomplishment," The Journal of Applied Behavioral Science, vol. 6, no. 4, pp. 387-400, December 1970.

[36] B. G. Piccoli and B. Ives, "Trust and the unintended effects of behavior control in virtual teams," MIS Quarterly, vol. 27, no. 3, pp. 365-396, September 2003.

[37] N. Gaan, "Collaborative tools and virtual team effectiveness: An inductively derived approach in India's software sector," Decision Sciences, vol. 39, no. 1, pp. 5-27, April 2012. 
[38] M. C. Lander, R. L. Purvis, G. E. McCary, and W. Leigh, "Trustbuilding mechanisms utilized in outsourced IS development projects A case study," Information and Management, vol. 41, no. 4, pp. 509 528, March 2004.

[39] A. C. Costa and N. Anderson, "Measuring trust in teams Development and validation of a multifaceted measure of formative and reflective indicators of team trust," European Journal of Work and Organizational Psychology, vol 20, no. 1, pp. 119-154, February 2011.

[40] D. Chan, "Functional relations among constructs in the same content domain at different levels of analysis: A typology of composition models," Journal of Applied Psychology, vol. 83, no. 2, pp. 234-246, April 1998.

[41] B. A. De Jong and K. T. Dirks, "Beyond shared perceptions of trust and monitoring in teams: implications of asymmetry and dissensus," Journal of Applied Psychology, vol. 97, no. 2, pp. 391-406, May 2012.

[42] R. M. Kramer, "Collective trust within organizations: Conceptual foundations and empirical insights," Corporate Reputation Review, vol. 13, no. 2, pp. 82-97, July 2010.

[43] B. McEvily, R. A. Weber, C. Bicchieri, and Y. T. Ho, "Can groups be trusted? An experimental study of trust in collective entities," in Handbook of Trust Research, 1st ed., R. Bachmann and A. Zaheer Eds. Cheltenham, UK: Edward Elgar Publishing, 2006, pp. 52- 67.

[44] S. A. Kiffin-Petersen and J. L. Cordery, "Trust, individualism and job characteristics as predictors of employee preference for teamwork," International Journal of Human Resource Management, vol. 14, no. 1, pp. 93-116, February 2003.

[45] G. Dietz, "Going back to the source: Why do people trust each other?", Journal of Trust Research, vol 1, no. 2, pp. 215-222, 2011.

[46] D. M. Rousseau, "Now let's make multi-level research on trust doable," Multi-level issues in organizational behavior and processes, no. 3, pp.159-166, 2004

[47] D. L. Ferrin, M. C. Bligh, and L. C. Kohles, "Can I trust you to trust me? A theory of trust, monitoring, and cooperation in interpersonal and intergroup relationships," Group \& Organization Management, vol. 32, no. 4, pp. 465-499, 2007.

[48] D. J. McAllister, "Affect- and cognition-based trust as foundations for interpersonal cooperation in organizations," Academy of Management Journal, vol. 38, no. 1, pp. 24-59, February 1995.

[49] G. Barczak, F. Lassk, and J. Mulki, "Antecedents of team creativity: An examination of team emotional intelligence, team trust and collaborative culture," Creativity and Innovation Management, vol. 19 , no. 4, pp. 332-345, November 2010.

[50] M. Williams, "In whom we trust: Group membership as an affective context for trust development," Academy of Management Review, vol. 26, no. 3, pp. 377-396, July 2001.

[51] M. A. Marks, J. E. Mathieu, and S. J. Zaccaro, "A temporally based framework and taxonomy of team processes," Academy of Management Review, vol. 26, no. 3, pp. 356-376, July 2001.

[52] S. W. Kozlowski and K. J. Klein (2000). A multilevel approach to theory and research in organizations: Contextual, temporal, and emergent processes," in Multilevel Theory, Research and Methods in Organizations: Foundations, Extensions, and New Directions, 1st ed., K. J. Klein and S. W. J. Kozlowski, Eds. San Francisco, CA: JosseyBass, 2000, pp. 3-90

[53] C. A. Fulmer and C. Ostroff, "Convergence and emergence in organizations: An integrative framework and review," Journal of Organizational Behavior, vol. 37, no. 51, pp. 122-145, February 2016.

[54] C. E. Naquin and T. R. Kurtzberg, "Team negotiation and perceptions of trustworthiness: The whole versus the sum of the parts," Group Dynamics: Theory, Research, and Practice, vol. 13, no. 2, pp. 133-150, June 2009 .

[55] A. Edmondson, "Psychological safety and learning behavior in work teams," Administrative Science Quarterly, vol. 44, no. 2, pp. 350-383. June 1999.

[56] R. Zolin, P. J. Hinds, R. Fruchter, and R. E. Levitt, "Interpersonal trust in cross-functional, geographically distributed work: A longitudinal study," Information and Organization, vol. 14, no. 1, pp. 1-26, January 2004.

[57] A. Cheshin, A. Rafaeli, and N. Bos, "Anger and happiness in virtual teams: Emotional influences of text and behavior on others' affect in the absence of non-verbal cues," Organizational Behavior and Human Decision Processes, vol. 116, no. 1, pp. 2-16, September 2011.

[58] S. G. Barsade, "The ripple effect: Emotional contagion and its influence on group behavior," Administrative Science Quarterly, vol. 47, no. 4, pp. 644-675, December 2002
[59] Oda, T. Naganawa, S. Yamauchi, N. Yamagata, and A. MatsumotoOda, Altruists are trusted based on non-verbal cues. Biology Letters, vol. 5 , no. 6 , pp. 752-754, July 2009.

[60] S. Centorrino, E. Djemai, A. Hopfensitz, M. Milinski, and P. Seabright, "Honest signaling in trust interactions: Smiles rated as genuine induce trust and signal higher learning opportunities," Evolution and Human Behavior, vol. 36, no. 1, pp. 8-16, January 2015.

[61] S. L. Jarvenpaa, K. Knoll, and D. E. Leidner, "Is anybody out there? Antecedents of trust in global virtual teams," Journal of Management Information Systems, vol. 14, no. 4, pp. 29-64, 1998.

[62] S. L. Jarvenpaa, T. R. Shaw, and D. S. Staples, "Toward contextualized theories of trust: The role of trust in global virtual teams," Information Systems Research, vol. 15, no. 3, pp. 250-267, September 2004

[63] B. A. Aubert and B. L. Kelsey, "Further understanding of trust and performance in virtual teams," Small Group Research, vol. 34, no. 5, pp. 575-618, October 2003.

[64] Zornoza, V. Orengo, and V. Peñarroja, "Relational capital in virtual teams: The role played by trust. Social Science Information, vol. 48 no. 2, pp. 257-281, June 2009.

[65] B. A. De Jong and T. Elfring, "Mediated and differential effects of trust on team performance: A study of ongoing work teams," Academy of Management Proceedings, vol. 1, no. 1, pp. 1-6, January 2007.

[66] M. D. Baer, L. van der Werff, J. A. Colquitt, J. B. Rodell, K. P. Zipay, and F. Buckley, "Trusting the 'Look and Feel': Situational normality, situational aesthetics, and the perceived trustworthiness of organizations," Academy of Management Journal, vol. 61, no. 5, pp. 1718-1740, October 2018.

[67] J. M. Wilson, S. G. Straus, and B. McEvily, "All in due time: The development of trust in computer-mediated and face-to-face teams," Organizational Behavior and Human Decision Processes, vol. 99, no. 1, pp. 16-33, January 2006.

[68] P. B. Lowry, R. M. Schuetzler, J. S. Giboney, and T. A. Gregory, "Is trust always better than distrust? The potential value of distrust in newer virtual teams engaged in short-term decision-making," Group Decision and Negotiation, vol. 24, no. 4, pp. 723-752, July 2015.

[69] J. Tanghe, B. Wisse, and H. van der Flier, "The role of group members affects the relationship between trust and cooperation," British Journal of Management, vol. 21, no. 2, pp. 359-374, June 2010.

[70] G. R. Jones and J. M. George, "The experience and evolution of trust: Implications for cooperation and teamwork," The Academy of Management Review, vol. 23, no. 3, pp. 531-546, July 1998.

[71] R. J. Lewicki, D. J. McAllister, and R. J. Bies, "Trust and distrust: New relationships and realities," Academy of Management Review, vol. 23 , no. 3, pp. 438-458, July 1998.

[72] C. W. Langfred, "Too much of a good thing? Negative effects of high trust and individual autonomy in self-managing teams," Academy of Management Journal, vol. 47, no. 3, pp. 385-399, 2004.

[73] F. Lyon, G. Möllering, and M. N. Saunders, "Introduction. Researching trust: the ongoing challenge of matching objectives and methods," in the Handbook of Research Methods on Trust. London, UK: Edward Elgar Publishing, 2015.

[74] S. S. Webber, "Leadership and trust facilitating cross-functional team success," Journal of Management Development, vol. 21, no. 3, pp. 201-214, April 2002.

[75] C. D. Dumitru, "Predictors of organizational trust: The relationship between organizational trust and organizational identification," International Conference on Marketing and Business Development Journal, vol. 1, no. 1, pp. 161-167, July 2015.

[76] D. Hamburger, "Project kick-off: getting the project off on the right foot," International Journal of Project Management, vol. 10, no. 2, pp. 115-122, May 1992

[77] A. Jones and D. Jones, "Improving teamwork, trust and safety: An ethnographic study of an interprofessional initiative," Journal of Interprofessional Care, vol. 25, no. 3, pp. 175-181, May 2011.

[78] C. D. Dumitru," Practices of building and maintaining trust in crossfunctional teams," Ph.D. dissertation, Dept. Business Administration, Jacobs University, Bremen, Germany, 2019.

Dr. Catalina Diana Dumitru holds a Master's degree in Psychology from the University of Bucharest, Romania. She was a doctoral researcher at the Bremen International School of Social Sciences and a visiting researcher at the Singapore Management University. In 2019, she received her doctoral degree in Business Administration from Jacobs University, Bremen, Germany. 
Alexandra Mittelstädt is a doctoral researcher at the Bremen International Graduate School of Social Sciences, Bremen, Germany. 